\title{
Anaphylaxis due to Red Imported Fire Ant sting
}

\author{
Graham O Solley, Cas Vanderwoude and Gregory K Knight
}

\begin{abstract}
The invasive Red Imported Fire Ant (Solenopsis invicta Buren) is well established at two locations in the Brisbane area, and we report a patient with anaphylaxis after a sting. The potential for anaphylactic events in Australia due to S. invicta will be greater than for native ants because of its unusual venom, its habit of forming supercolonies in grassy areas, and its aggressive group territorial defence, which can result in multiple stings. (MJA 2002; 176: 521-523)
\end{abstract}

STINGS FROM INSECTS of the Order Hymenoptera (bees, wasps and ants) are responsible for numerous anaphylactic events, some fatal. ${ }^{1,2}$ In Australia, allergic reactions to ant stings have, until now, been caused by native ant species (eg, the jumper ant [Myrmecia pilosula and other Myrmecia spp.], ${ }^{3-5}$ the greenhead ant [Rhytidoponera metallica], Odontomachus, Cerapachys and Brachyponera spp.). Although ants are found worldwide, the only other ant species commonly reported as inducing anaphylaxis is the Red Imported Fire Ant (Solenopsis invicta Buren), ${ }^{6-9}$ which is native to Brazil, Paraguay, Uruguay and Argentina. ${ }^{10}$ This species was accidentally introduced into Alabama in the United States in the $1930 \mathrm{~s},{ }^{10,11}$ and since then has spread rapidly throughout the southern United States, causing economic damage to crops and primary industries, reducing biological diversity, and frequently inflicting severe stings to humans. ${ }^{12}$

In February 2001, two well established populations of $S$. invicta ants were discovered in Brisbane (Box 1). The mode of introduction is unknown, although it may have been through the transport of infested sea cargo. It is estimated that the incursion is more than five years old. Currently, $S$. invicta ants are found over 37000 hectares of the Brisbane region, covering over 64000 homes.

Here, we describe a patient with anaphylaxis as a result of $S$. invicta stings, document his treatment and estimate the likely rates of anaphylaxis and mortality should these ants spread across the remainder of Australia.

\section{Clinical record}

A man, aged 47 years, began work as a gardener at the Port of Brisbane in November 1999. His first Red Imported Fire Ant (RIFA) sting occurred during the summer of 19992000. These stings resulted in acute local pain at the sting

\section{For editorial comment, see page 518}

Watkins Medical Centre, Brisbane, QLD.

Graham O Solley, MB BS, FACP, Allergist.

Fire Ant Control Centre, Oxley, QLD.

Cas Vanderwoude, ADipAppSc(For), BAppSc(Hons), PhD,

Principal Scientist.

Royal Brisbane Hospital, Brisbane, QLD.

Gregory K Knight, MB BS, MPH, FAFOM, Consulting Occupational

Physician to Port of Brisbane Corporation.

Reprints: Dr Graham O Solley, Watkins Medical Centre, 225 Wickham

Terrace, Brisbane, QLD 4000

solleybg@futureweb.com.au

\section{1: Map of Brisbane, showing areas infested and putatively infested with the Red Imported Fire Ant (Solenopsis invicta) shaded yellow, main roads (grey) and council boundaries (dashed)}

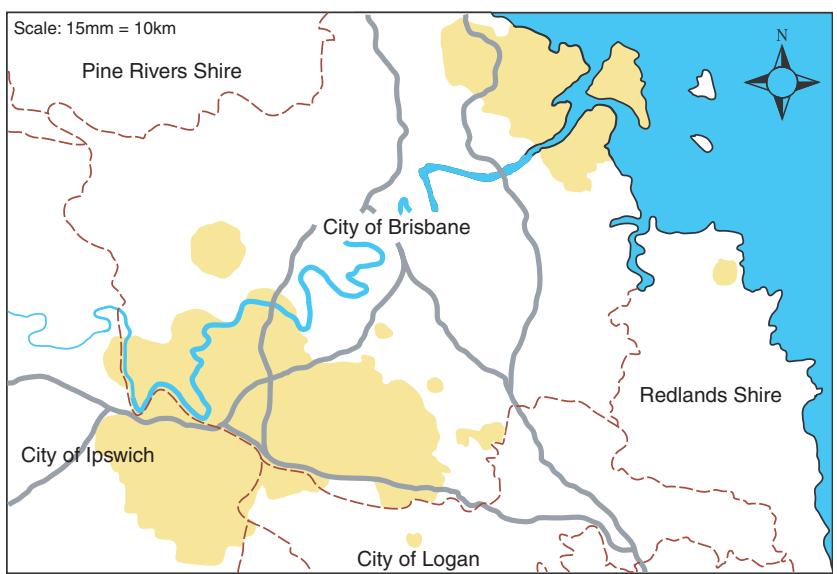

site, leading to small pustules the following day which took two weeks to heal (a typical reaction, unique to RIFA stings, which occurs in about $85 \%$ of cases). ${ }^{10}$ These reactions were quite different from previous stings by greenhead ants, which left nothing more than local puncture marks.

$\mathrm{He}$ was then assigned to a work party to search and destroy RIFA nests. In this task he incurred 20 to 30 separate RIFA sting events, which resulted in reactions similar to those described above.

He then received two RIFA stings on his knee at the one time. Ten minutes later, he developed extreme pruritus and burning of both feet. This was quickly followed by generalised pruritus, nasal congestion, and acute tightness of his throat and chest with dyspnoea. He was transported quickly to a nearby hospital. On arrival, a rash was present on his trunk and legs, his pulse rate was 84 beats $/ \mathrm{min}$, his blood pressure was $131 / 110 \mathrm{mmHg}$ and his lungs were clear. $\mathrm{He}$ was given intravenous saline and $200 \mathrm{mg}$ of hydrocortisone, but not adrenalin. Two hours later, he was discharged well.

A review by the Port of Brisbane's occupational physician highlighted this as a sentinel case and the causal agent was identified as RIFA. The patient's usual work duties were altered to avoid further, possibly life-threatening, RIFA stings. He was also provided with the semi-automatic adrenalin device, EpiPen (CSL, Melbourne). Avoidance meas- 


\section{2: Biology and epidemiology of Red Imported Fire Ants}

Red Imported Fire Ants are inconspicuous, reddish-brown ants with no distinguishing features visible to the naked eye. Superficially, they resemble many common native and exotic ant species present in the Brisbane region (Figure 1). They range in size from $2 \mathrm{~mm}$ to $6 \mathrm{~mm}$, with many intermediate-sized individuals. Optimum habitats include grassed areas, gardens, sites near flowing and still water and recently disturbed soil. Fire ant nests (Figure 2) are largely subterranean and are conspicuous by an above-ground, dome-shaped mound which can be as high as $45 \mathrm{~cm}$ above normal ground level (usually $20-30 \mathrm{~cm}$ ). Normally, the above-ground part of the nest resembles a mound of excavated soil, $30-60 \mathrm{~cm}$ in diameter, but sometimes these are absent. The nests of many native ants have obvious openings through which ants enter and exit.

Two forms of Red Imported Fire Ants have been discovered in Brisbane: the monogynous (single-queen) and polygynous (multiple-queen) types. Monogyne colonies maintain territory independently from neighbouring colonies. As a result, the distance between colonies is normally greater than 10 metres, as this avoids unnecessary conflict between neighbouring colonies over territory. However, worker ants from polygyne colonies can not determine whether other fire ant workers or queens they encounter are related to them and, as a result, coalesce to form large, dense supercolonies. These polygyne infestations, which are dominant in Brisbane, present a greater hazard due to the much larger numbers of ants a site can support (thousands of polygyne colonies per hectare instead of hundreds of monogyne colonies per hectare)

Both forms defend their territory aggressively and make extensive use of pheromones or chemical signals to recruit other workers, synchronise attacks and initiate stinging. For this reason, multiple stings are the rule rather than the exception (Figure $3 \mathrm{a}-\mathrm{d}$ ). Their diet is unspecialised and they feed on any available sources of carbohydrates, lipids and protein.

Currently, over 37000 hectares of Brisbane's eastern and south-western suburbs are putatively infested with $S$. invicta (Figure 1). However, an eradication program has been initiated by the Queensland Department of Primary Industries at a cost exceeding $\$ 123$ million over the next five years. This program is jointly funded by the Commonwealth Government and all Australian States and Territories.

The potential for anaphylactic events in Australia due to S. invicta will be higher than for other native ants due to three key factors:

- The venom of $S$. invicta is unusual, being composed largely of alkaloids, but also including four different proteins. ${ }^{15,16}$ These proteins, as well as the non-protein components of the venom, are each individually capable of inducing anaphylaxis.

- The polygynous form of $S$. invicta often completely dominates areas where it has invaded, forming interconnected supercolonies. ${ }^{17}$ Coupled with grassy areas as its preferred habitat, the probability of contact with humans is high.

- Aggressive pheromone-driven group defence of territory and the colony results in a high probability of multiple stings.

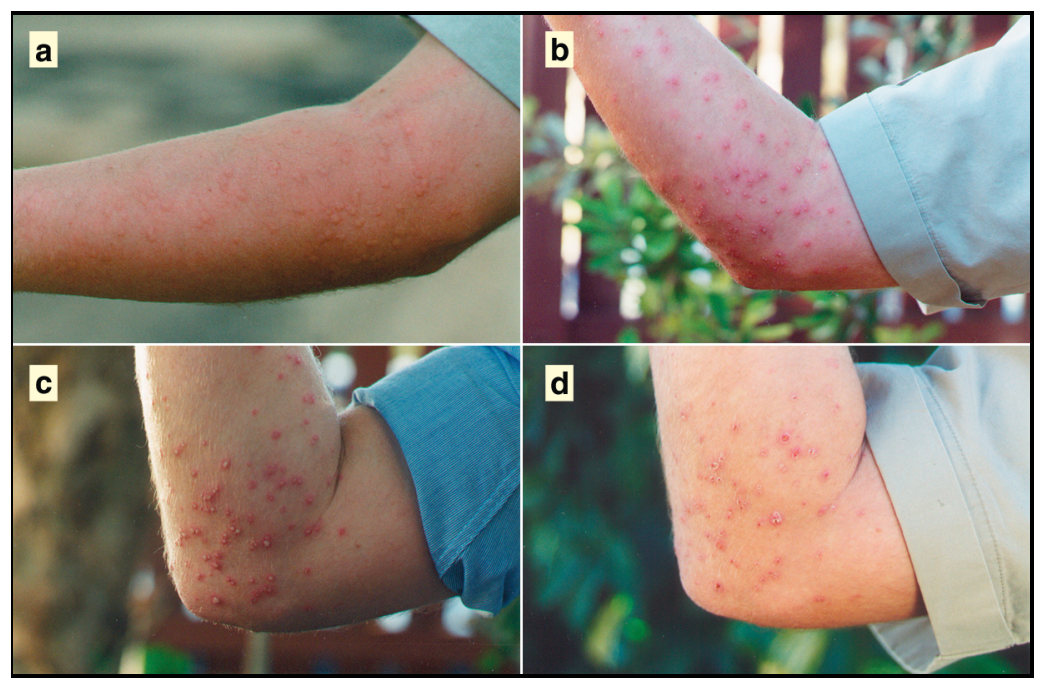

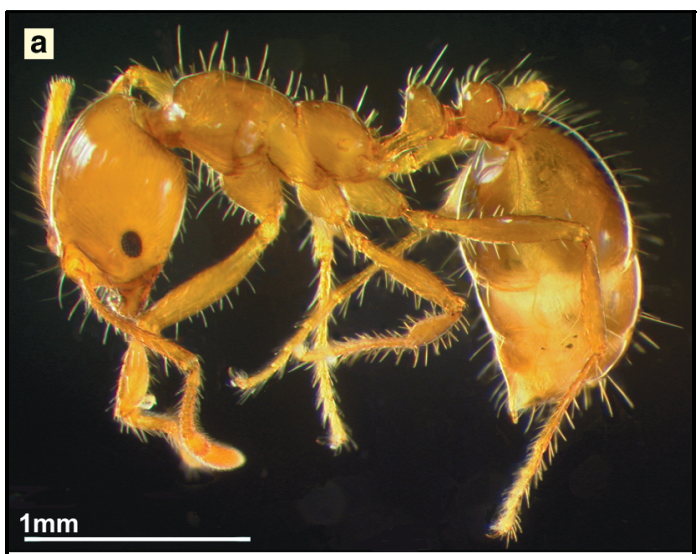

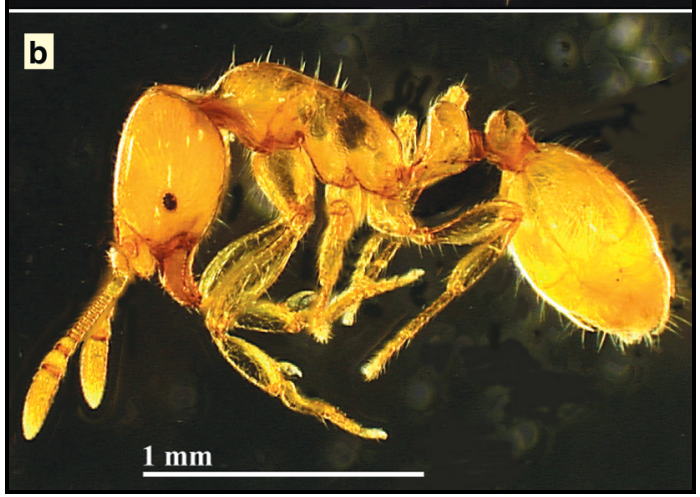

- 1: (a) The Red Imported Fire Ant (Solenopsis invicta), and (b) Monomorium sp, a harmless native ant, demonstrating the similarity between the two species (with permission, Macquarie University, School of Biological Sciences).

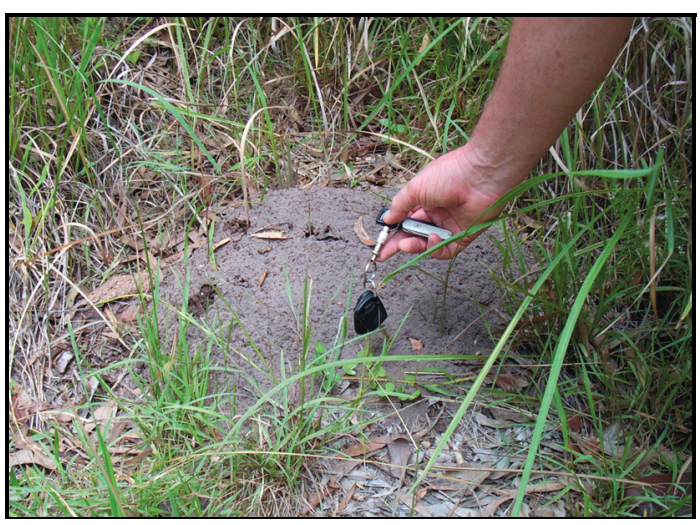

- 2: A typical Red Imported Fire Ant mound (with permission, Queensland Department of Primary Industries).

13: Multiple stings (about 150) by S. invicta to the right arm of one of the authors $(C \mathrm{~V})$ as a result of accidental exposure in the field. (a) Five minutes after the event, showing raised welts at sting sites; (b) 18 hours after, showing typical pustules; (c) 48 hours after; and (d) seven days after the event. 
ures were successful, although he subsequently sustained a number of stings from greenhead ants and wasps without adverse responses.

Skin-prick testing with the whole-body extract of $S$. invicta (supplied by Stallergenes, Paris, France) showed a $10-\mathrm{mm}$ weal to the $1: 1000$ dilution, thus confirming the occupational physician's initial diagnosis. As a consequence, he began desensitisation with $S$. invicta whole-body extract in accordance with accepted treatment guidelines. ${ }^{13} \mathrm{He}$ has now reached the "maintenance phase" of the schedule (ie, $0.5 \mathrm{~mL}$ of the $1: 10$ dilution). Subsequent to desensitisation, he reported one RIFA sting, which caused only the expected localised pustule.

\section{Discussion}

Adrenalin is the first-aid treatment of choice for a systemic allergic response with dyspnoea and/or hypotension. ${ }^{14}$ It achieves the quickest reversal of the adverse events and is very safe in a life-threatening situation. Anyone who has had stinging-insect-induced anaphylaxis should carry an EpiPen (or EpiPen Jr for children; CSL) for immediate first-aid use if hypotension or dyspnoea occurs. Specific desensitisation to prevent future anaphylaxis to RIFA stings in susceptible patients is effective, ${ }^{13}$ and anyone suspected of RIFA sting anaphylaxis should be referred to an allergist for assessment.

Taxonomically, S. invicta is in a different subfamily (Myrmicinae) from that of Australian native ants responsible for anaphylactic events. Furthermore, RIFA venom is unlike that of any other Australian Hymenoptera species. As a consequence, there is a strong possibility that allergic crossreactivity between species does not occur, as is the case in the United States. Indeed, our patient's experience would support this belief. Therefore, RIFA toxin represents a new risk to a portion of the Australian population not yet aware of this. The biology and epidemiology of $S$. invicta is summarised in Box 2.

In the United States, over 40 million people live in areas infested by $S$. invicta. Annually, 14 million people are stung, a quarter of whom are expected to develop some sensitivity to RIFA toxin. ${ }^{10}$ An examination of habitat preferences and estimates of the rate of uncontrolled spread suggest that, unless eradicated, $S$. invicta will occupy much of arable Australia within 30 years, and therefore exist in close proximity to a large portion of the Australian population. Only areas with extremes of aridity and cold would remain free of these ants. It is reasonable to expect that proportionally similar numbers of people will come into contact with fire ants in Australia and experience similar reactions to their stings.

A survey of 1286 practitioners in South Carolina (USA) (population, four million), where fire ants are well established, ${ }^{7}$ estimated that annually over 33000 people (94 per 10000 population) seek medical consultation for RIFA stings, and, of these, 660 people (1.9 per 10000 population) are treated for anaphylaxis. Direct extrapolation of these data to the Australian situation would suggest that about 140000 consultations and 3000 anaphylactic reac- tions are to be expected each year by 2030 if RIFA eradication is not successful.

\section{Competing interests}

None declared. The decision to submit this article was made by us and not influenced by any funding body. G O S is in private practice and self-funded; $\mathrm{C}$ is supported by the Queensland Department of Primary Industries Fire Ant Control Centre; and G K K is supported by the Port of Brisbane Corporation.

\section{References}

1. Harvey P, Sperber S, Kette F. Bee sting mortality in Australia. Med J Aust 1984; 140: 209-211.

2. McGain F, Harrison J, Winkel KD. Wasp sting mortality in Australia. Med J Aust 2000; 173: 198-200

3. Brown $\mathrm{SA}, \mathrm{Wu} \mathrm{Q}, \mathrm{Kelsall} \mathrm{GRH}$, et al. Fatal anaphylaxis following jack jumper ant sting in southern Tasmania. Med J Aust 2001; 175: 644-647.

4. Clarke PS. The natural history of sensitivity to jack jumper ants (Hymenoptera formicidae Myrmecia pilosula) in Tasmania. Med J Aust 1986; 145: 564-566.

5. Solley GO. Allergy to stinging and biting insects in Queensland. Med J Aust 1990; 153: 650-654.

6. Stafford CT. Hypersensitivity to fire ant venom. Ann Allergy Asthma Immunol 1996; 77: 87-95

7. Caldwell ST, Schuman SH, Simpson WM, Jr. Fire ants: a continuing community health threat in South Carolina. J South Carolina Med Assoc 1999; 95: 231-235.

8. Rhoades RB, Stafford CT, James FK Jr. Survey of fatal anaphylactic reactions to imported fire ants stings. J Allergy Clin Immunol 1989; 84: 159-162.

9. Prahlow JA, Barnard JJ. Fatal anaphylaxis due to fire ant stings. Am J Forensic Med Pathol 1998; 19: 137-142

10. Taber SW. Fire ants. College Station, Tex: Texas A\&M University Press, 2000: 1308

11. Lofgren CS, Banks WA, Glancey BM. Biology and control of imported fire ants. Annu Rev Entomol 1975; 20: 1-30

12. deShazo RD, Griffing C, Kwan TH, et al. Dermal hypersensitivity reactions to imported fire ants. J Allergy Clin Immunol 1984; 74: 841-847.

13. Freeman TM, Hylander R, Ortiz A, Martin ME. Imported fire ant immunotherapy: effectiveness of whole body extracts. J Allergy Clin Immunol 1992; 90: 210-215.

14. Medical management of severe anaphylactoid and anaphylactic reactions. Australian Prescriber 2001; Vol No. 24.

15. Hoffman DR, Dove DE, Jacobson RS. Allergens in Hymenoptera venom XX. Isolation of four allergens from imported fire ant (Solenopsis invicta) venom. $J$ Allergy Clin Immunol 1988; 82: 818-827.

16. Baer H, Liu TY, Anderson MC, et al. Protein components of fire ant venom (Solenopsis invicta). Toxicon 1979; 17: 397-405.

17. Nattrass R, Vanderwoude C. A preliminary investigation of the ecological effects of Red Imported Fire Ants (Solenopsis invicta) in Brisbane. Ecological Manage Restoration 2001; 2: 220-223.

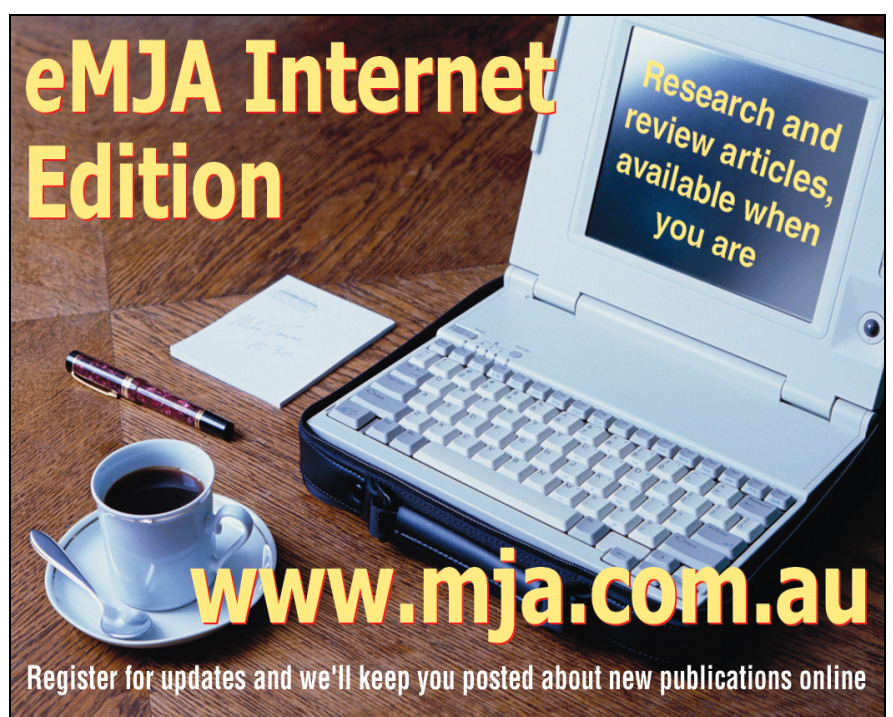

